\title{
Transcriptome Profiling Reveals the Effects of Nitric Oxide on the Growth and Physiological Characteristics of Watermelon under Aluminum Stress
}

\author{
Yangxia Zheng ${ }^{\dagger}$, Jiachang Xiao ${ }^{\dagger}$, Kaimin Zheng, Junying Ma, Maolin He, Jie Li and Mengyao Li *(D) \\ College of Horticulture, Sichuan Agricultural University, Chengdu 611130, China; \\ zhengyx13520@sicau.edu.cn (Y.Z.); scnydxxjc@163.com (J.X.); zhengkaimin111@163.com (K.Z.); \\ ma19993888137@163.com (J.M.); hemaolin821@163.com (M.H.); li1272135958@163.com (J.L.) \\ * Correspondence: limy@sicau.edu.cn \\ + These authors contributed equally to this work.
}

Citation: Zheng, Y.; Xiao, J.; Zheng, K.; Ma, J.; He, M.; Li, J.; Li, M. Transcriptome Profiling Reveals the Effects of Nitric Oxide on the Growth and Physiological Characteristics of Watermelon under Aluminum Stress. Genes 2021, 12, 1735. https:// doi.org/10.3390/genes12111735

Academic Editor: Qingyi Yu

Received: 13 October 2021

Accepted: 28 October 2021

Published: 29 October 2021

Publisher's Note: MDPI stays neutral with regard to jurisdictional claims in published maps and institutional affiliations.

Copyright: () 2021 by the authors. Licensee MDPI, Basel, Switzerland. This article is an open access article distributed under the terms and conditions of the Creative Commons Attribution (CC BY) license (https:// creativecommons.org/licenses/by/ $4.0 /)$.

\begin{abstract}
Excessive aluminum ions $\left(\mathrm{Al}^{3+}\right)$ in acidic soil can have a toxic effect on watermelons, restricting plant growth and reducing yield and quality. In this study, we found that exogenous application of nitric oxide (NO) could increase the photochemical efficiency of watermelon leaves under aluminum stress by promoting closure of leaf stomata, reducing malondialdehyde and superoxide anion in leaves, and increasing POD and CAT activity. These findings showed that the exogenous application of $\mathrm{NO}$ improved the ability of watermelon to withstand aluminum stress. To further reveal the mitigation mechanism of $\mathrm{NO}$ on watermelons under aluminum stress, the differences following different types of treatments-normal growth, $\mathrm{Al}$, and $\mathrm{Al}+\mathrm{NO}$-were shown using de novo sequencing of transcriptomes. In total, 511 differentially expressed genes (DEGs) were identified between the $\mathrm{Al}+\mathrm{NO}$ and $\mathrm{Al}$ treatment groups. Significantly enriched biological processes included nitrogen metabolism, phenylpropane metabolism, and photosynthesis. We selected 23 genes related to antioxidant enzymes and phenylpropane metabolism for qRT-PCR validation. The results showed that after exogenous application of NO, the expression of genes encoding POD and CAT increased, consistent with the results of the physiological indicators. The expression patterns of genes involved in phenylpropanoid metabolism were consistent with the transcriptome expression abundance. These results indicate that aluminum stress was involved in the inhibition of the photosynthetic pathway, and NO could activate the antioxidant enzyme defense system and phenylpropane metabolism to protect cells and scavenge reactive oxygen species. This study improves our current understanding by comprehensively analyzing the molecular mechanisms underlying NO-induced aluminum stress alleviation in watermelons.
\end{abstract}

Keywords: transcriptome; watermelon; nitric oxide; aluminum stress; physiological characteristics

\section{Introduction}

Watermelon (Citrullus lanatus (Thunb.) Matsum. et Nakai) is an annual vine belonging to the Cucurbitaceae family and widely cultivated all over the world [1]. According to the FAO data in 2019 (https: / / scienceagri.com/10-worlds-biggest-watermelon-producing-countries/, accessed on 27 October 2021), China is the world's largest producer of watermelon, with the planting area, output, and consumption ranking first in the world. In recent years, it has been reported that the acidification of the soil led to increased mobile aluminum contents, being one of the reasons for continuous cropping obstacle of watermelon [2]. Importantly, aluminum stress has been documented to inhibit the growth and development of watermelon on acid soil and seriously affect the yield and quality.

Acidic soil accounts for about $30 \%$ of the world's ice-free land area [3]. Given that acidic soils are widely distributed in southern China, aluminum toxicity in acidic soils has been reported as a significant factor limiting local crop production [4]. The most 
notable feature of aluminum toxicity is that it inhibits the growth of plant root tips and causes damage to root tip cells, thus affecting the absorption of mineral elements and finally stunting plant growth [5]. To adapt to aluminum toxicity in acidic soils, plants have evolved various resistance mechanisms, mainly external rejection and internal aluminum tolerance mechanisms [6]. External aluminum rejection mechanisms predominantly involve the chelation of malic acid, citric acid, and oxalate with $\mathrm{Al}^{3+}$ to form non-toxic compounds in the rhizosphere, preventing aluminum ions from entering root tip cells. In contrast, the aluminum tolerance mechanism involves detoxifying and isolating aluminum from vacuoles and transferring aluminum ions that enter the cell to the vacuole to reduce aluminum toxicity.

Nitric oxide (NO) is a small signal molecule that exists as free radicals in plants. It is considered a new type of gas transfer element that can regulate plant growth and development and transmit information to improve the resilience of plants under stress $[7,8]$. Importantly, NO has been reported to be directly involved in regulating plant growth and stress response. In this regard, studies have shown that any stress could stimulate the production of reactive oxygen species (ROS) in plants, and NO could react with various forms of oxygen to reduce ROS accumulation in plants [9]. NO could also improve the activity of antioxidant enzymes in plants, remove ROS produced in vivo, and ultimately reduce malondialdehyde (MDA, a membrane peroxidation product) levels. In addition, NO has also been documented to delay degradation of chlorophyll content, enhance photosynthesis, regulate the stomatal aperture, and reduce damage to the photosynthetic electron transport chain under stress conditions $[10,11]$. Current studies have shown that NO could promote root elongation and growth of soybean, rice, and Arabidopsis under aluminum stress and reduce the accumulation of aluminum ions in root tips [12-14]. However, the molecular mechanisms underlying NO-induced aluminum stress in watermelon alleviation remain unclear. In the present study, plant physiology and molecular biology techniques were combined to explore mechanisms underlying the effects of exogenous $\mathrm{NO}$ on watermelon seedlings under aluminum stress conditions. These findings will help improve our understanding by comprehensively analyzing the mechanisms underlying NO-induced aluminum stress alleviation in watermelons.

\section{Materials and Methods}

\subsection{Plant Material and Experimental Design}

Evenly sized, healthy and plump watermelon seeds were selected (variety Zaojia 8424, produced by Shandong Shouhe seed industry; hybrid; characteristics: medium plant growth, strong disease resistance, planted in a large area in south China), soaked in water at $55^{\circ} \mathrm{C}$ for $15 \mathrm{~min}$, cooled to room temperature for another $6 \mathrm{~h}$, and then placed in an incubator at $30{ }^{\circ} \mathrm{C}$ to accelerate germination. After germination, we sowed the seeds in a hole dish (the volume ratio of perlite, vermiculite, and organic fertilizer was 4:3:1), and transplanted the seedlings to a $10 \times 10 \mathrm{~cm}$ nutrition bowl when they grew one leaf. The roots of watermelon seedlings with three leaves were treated with $50 \mathrm{~mL}$ treatment solution of different concentrations (CK: normal growth; Al: $1200 \mu \mathrm{mol} / \mathrm{L}$ $\mathrm{Al}_{2}\left(\mathrm{SO}_{4}\right)_{3} \cdot 18 \mathrm{H}_{2} \mathrm{O}, \mathrm{pH}=4.5 ; \mathrm{Al}+\mathrm{NO}: 1200 \mu \mathrm{mol} / \mathrm{L} \mathrm{Al}_{2}\left(\mathrm{SO}_{4}\right)_{3} \cdot 18 \mathrm{H}_{2} \mathrm{O}+100 \mu \mathrm{mol} / \mathrm{L} \mathrm{SNP}$, $\mathrm{pH}=4.5)$. After three days of treatment, samples were taken and stored at $-80^{\circ} \mathrm{C}$ after treatment with liquid nitrogen for later use. Each treatment was set up for three biological replicates. The test site was the Plant Factory at the College of Horticulture, Sichuan Agricultural University. The temperature, light intensity, relative humidity, and light/dark period were set as $25^{\circ} \mathrm{C}, 5000 \mathrm{~lx}, 75 \%$, and $16 \mathrm{~h} / 8 \mathrm{~h}$, respectively.

\subsection{Determination of Growth Indicators}

After ten days of treatment, five seedlings were randomly selected for growth index determination for each treatment. The root length and plant height were measured with a ruler (the dividing point was the node position of the rhizome), and the fresh weight and dry weight of the seedlings were weighed and recorded with an electronic scale. 


\subsection{Determination of Leaf Index}

2.3.1. Determination of Chlorophyll Fluorescence and Photosynthetic Parameters

After three days of treatment, chlorophyll fluorescence and photosynthetic parameters were measured. The chlorophyll fluorescence parameters of the second true leaf of watermelon seedlings were measured using a chlorophyll fluorescence analyzer (PAM2500, Walz, Nuremberg, Germany). The leaves of watermelon seedlings were placed in a dark room for $30 \mathrm{~min}$ after dark adaptation to determine the slow fluorescence induction curve.

The net photosynthetic rate (Pn), stomatal conductance (Gs), intercellular $\mathrm{CO}_{2}$ concentration $(\mathrm{Ci})$, and transpiration rate (Tr) of the third fully expanded leaf (from top to bottom) were determined using an infrared gas analyzer portable photosynthesis system (Li-6400; LI-COR, Inc., Lincoln, NE, USA) between 10 a.m. and 11 a.m. The cuvette conditions for data measurement consisted of photosynthetic photon flux density (PPFD) of $1000 \mu \mathrm{mol}$ photons $\mathrm{m}^{-2} \mathrm{~s}^{-1}$, relative humidity at $60-70 \%$, temperature of $25^{\circ} \mathrm{C}$, and external $\mathrm{CO}_{2}$ concentration of $400 \pm 10 \mu \mathrm{mol} \mathrm{mol}^{-1}$.

\subsubsection{Determination of Stomata and Leaf Tissue Sections}

After three days of treatment, the second watermelon leaf was completely unfolded, and colorless nail polish was applied to the middle part of the lower epidermis of leaves by the imprinting method. After $20 \mathrm{~min}$, the nail polish flakes were completely dried with tweezers and made into temporary sections [15]. Stomatal characteristics were observed by optical microscope (Nikon Eclipse E100, Nikon, Tokyo, Japan). Stomatal density, the length (a) and width (b) of stomatal apparatus, stomatal aperture (M), and stomatal area (S) were measured using Image software. The stomatal aperture and stomatal area were calculated using the following formula:

$$
\mathrm{M}=\mathrm{b} / \mathrm{a}, \mathrm{S}=\Pi \times \mathrm{a} \times \mathrm{b} / 4,
$$

where $a$ is the length, $b$ is width, and $\Pi$ is 3.14 .

The middle part of the watermelon leaf was selected (the midrib avoided) and cut into rectangular pieces of about $1 \mathrm{~cm} \times 1 \mathrm{~cm}$. After fixation with FAA (formaldehyde-acetic acid alcohol), a series of operations, including dehydration, wax immersion, and embedding, was performed, and a paraffin section was made. A microtome (RM2016, leica, Frankfurt, Germany) was used to cut $6 \mu \mathrm{m}$-thick slices. After spreading, baking, dewaxing, and Safranin $\mathrm{O} /$ fast green staining of the wax slices, the characteristics of the cross-section of the leaf were observed under an optical microscope, using an imaging system (Nikon DS-U3, Nikon, Tokyo, Japan). Image acquisition and analysis were performed, and the thickness of the leaf, epidermis, and mesophyll were measured using ImageJ microscopy software.

\subsection{Determination of Physiological Indicators}

After five days of treatment, fully unfolded mature leaves were selected for measurement. The measured indicators included chlorophyll content, superoxide dismutase activity, peroxidase activity, catalase activity, malondialdehyde content, electrolyte permeability, superoxide anion [16], nitrate reductase activity [17], and nitrogen element content [18]. SPSS22.0 was used for significance analysis, and Orign2019b was used for mapping.

\subsection{RNA Extraction, Library Construction, and Sequencing}

After the watermelon leaf sample was ground into powder with liquid nitrogen, Trizol extract was used to extract total RNA (Invitrogen, Carlsbad, CA, USA), according to the manufacturer's instructions. A spectrophotometer was used to detect the quality and purity of the RNA, and $1.5 \%$ agarose gel electrophoresis was used to detect the integrity of the RNA (Table S1). Oligo (dT) magnetic beads were used to enrich the mRNA with polyA. Randomly interrupted mRNA fragments were then used as a template to synthesize the first cDNA strand. Finally, a buffer solution, dNTPs, RNaseH, and DNA polymerase I were added to synthesize the second cDNA. The purified double-strand was enriched by PCR 
to obtain a cDNA library. Finally, Beijing Novogene Bioinformatics Technology Co. Ltd. (Beijing, China) was commissioned to perform high-throughput sequencing based on the Illumina Hiseq 2500 technology sequencing platform.

\subsection{Sequence Assembly and Gene Annotation}

Data filtering was performed on the raw reads produced by the Illumina Hiseq 2500 sequencing platform to obtain high-quality clean reads by removing linker sequences and low-quality reads. The draft genome sequence of watermelon was used as a reference (http:/ / cucurbitgenomics.org/ftp/genome/watermelon/97103/v2/, accessed on 5 March 2021). Trinity software was used to merge and assemble all clean reads to obtain the genes. DEG sequences were compared to GO and KEGG databases to obtain annotation results.

\subsection{Screening and Classification of DEGs}

EBSeq was used for differential expression analysis to obtain DEG data sets from the two libraries. The False Discovery Rate (FDR) was used as a key indicator for the screening of DEGs. During the screening process, FDR (q-value) $<0.05$ and $\mid \log 2$ (foldchange) $\mid \geq 0$ were used as the screening criteria.

\subsection{Verifying Gene Expression Levels by $q R T-P C R$}

The expression levels of 23 genes were verified by qRT-PCR, and primer Premer6 was used to design specific primers (Table $\mathrm{S} 2$ ). The cDNA of $\mathrm{CK}, \mathrm{Al}$, and $\mathrm{Al}+\mathrm{NO}$ were used as the template. The reaction procedure consisted of pre-denaturation at $95{ }^{\circ} \mathrm{C}$ for $30 \mathrm{~s}$, then denaturation at $95^{\circ} \mathrm{C}$ for $5 \mathrm{~s}$ and annealing at $55^{\circ} \mathrm{C}$ for $1 \mathrm{~min}$. Dissolution curves were drawn after 40 cycles to determine the specificity of the primers. The experiment was repeated three times. The relative expression levels of target genes were normalized by the geometric mean of ClYLS8 expression levels and then calculated using the $2^{-\Delta \Delta C T}$ method [19].

\section{Results}

\subsection{Effects of NO on Watermelon Growth under Aluminum Stress}

As illustrated in Figure 1, aluminum stress significantly inhibited the growth and biomass accumulation of watermelon, documented in terms of decreased fresh weight (b), dry weight (c), root length (d), and plant height (e). In contrast, the exogenous application of $\mathrm{NO}$ alleviated the adverse effects of aluminum on watermelon growth and significantly increased the plant height, root length, and biomass of watermelon seedlings.

\subsection{Effects of NO on Photosynthesis of Watermelon under Aluminum Stress}

\subsubsection{The Effect of NO on Photosynthetic Parameters and Chlorophyll Fluorescence} Parameters under Aluminum Stress

As seen in Figure 2, the chlorophyll content, carotenoids, net photosynthetic rate, stomatal conductance, and transpiration rate of aluminum-stressed watermelon leaves were significantly reduced compared with $\mathrm{CK}$. The intercellular $\mathrm{CO}_{2}$ concentration increased, but there was no statistically significant difference. After the exogenous application of NO, the chlorophyll and carotenoids contents in watermelon leaves were significantly higher than that of Al-exposed watermelon leaves. However, the net photosynthetic rate, stomatal conductance, intercellular $\mathrm{CO}_{2}$ concentration, and transpiration rate were significantly lower than in Al-exposed watermelon leaves. This finding indicates that after exogenous application of $\mathrm{NO}$, the stomata of watermelon leaves were closed, and the photosynthetic rate was decreased. 

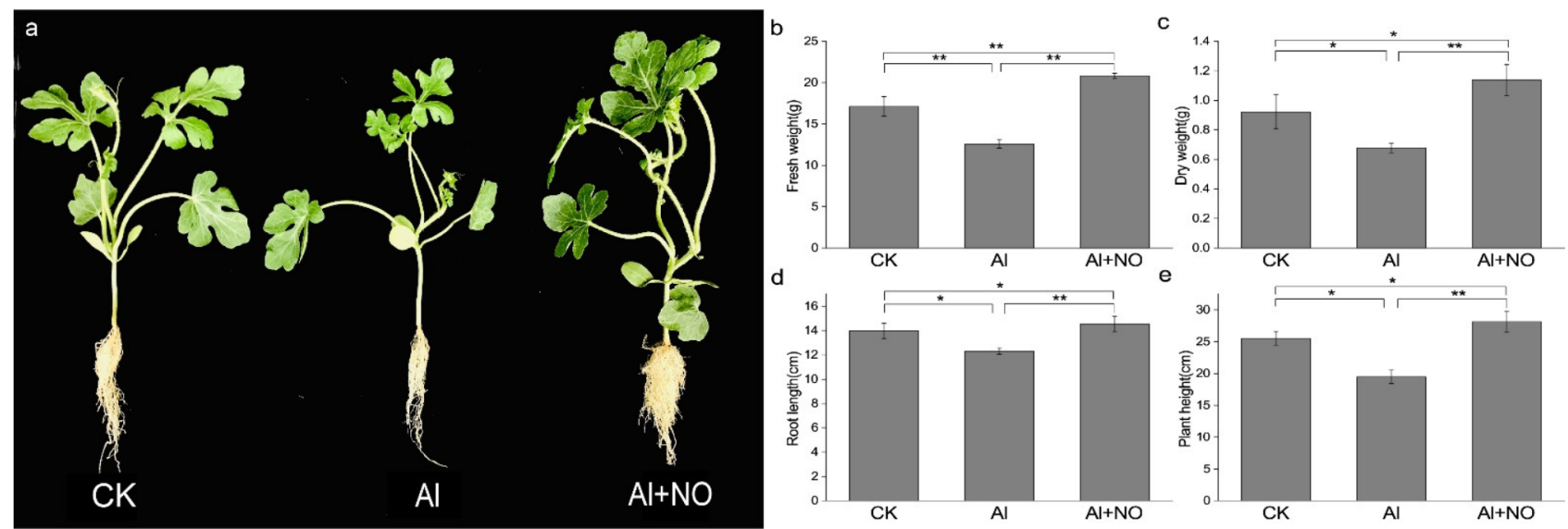

Figure 1. Effects of $\mathrm{NO}$ on watermelon growth under aluminum stress. (a) Phenotypes of plants following different treatments. (b-e) Measurements after three days for (b) fresh weight, (c) dry weight, (d) root length, and (e) plant height. Data are presented as means $\pm \mathrm{SD}$ of three biological replicates. Asterisks indicate significant differences $\left({ }^{*} p<0.05\right.$, ** $p<0.01$ ) between the means of the treatment groups and the control groups.
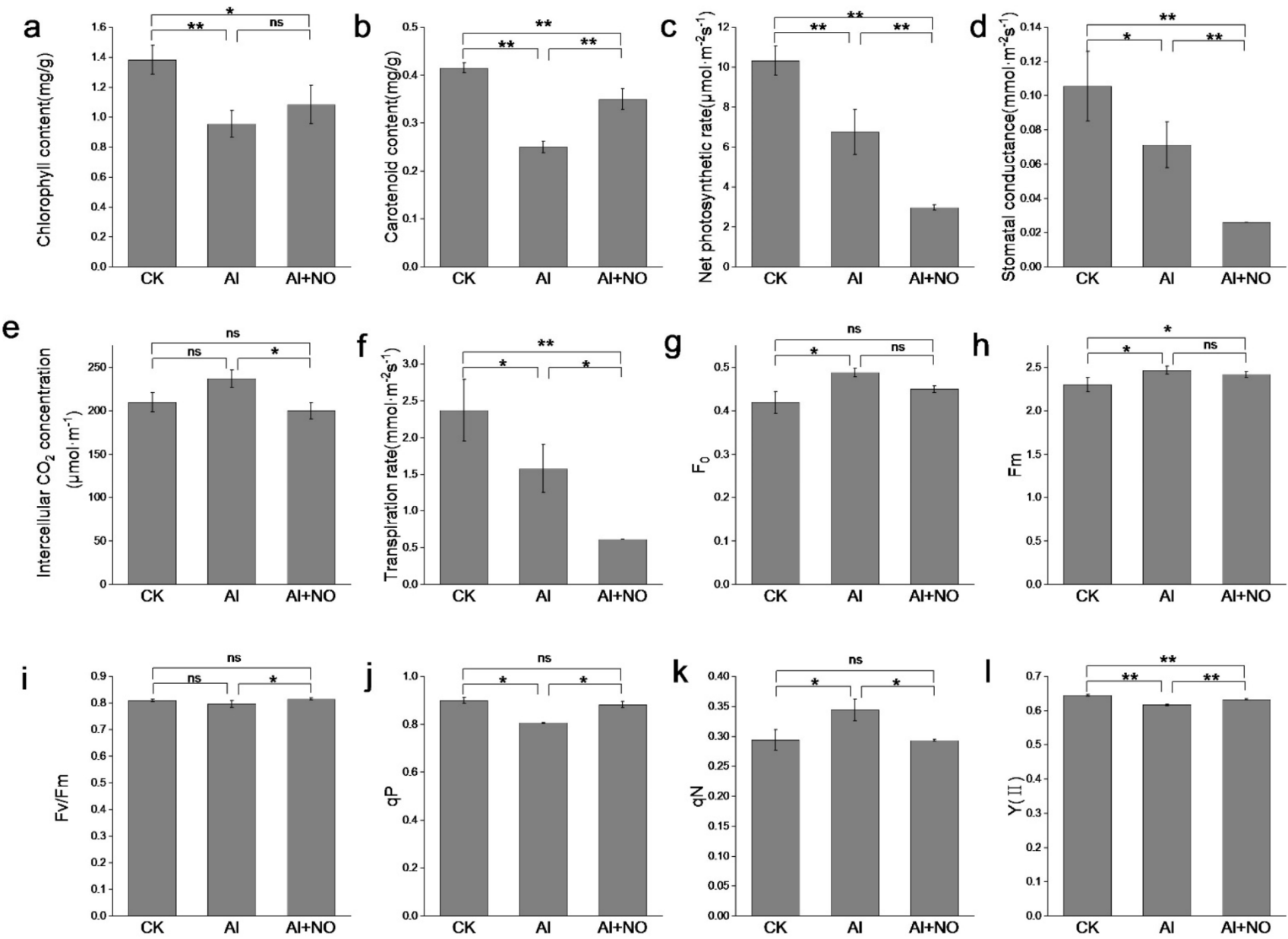

Figure 2. Effects of nitric oxide on photosynthetic parameters and chlorophyll fluorescence parameters of Al-exposed watermelon. (a) Chlorophyll content, (b) carotenoid content, (c) net photosynthetic rate, (d) stomatal conductance, (e) intercellular $\mathrm{CO}_{2}$ concentration, (f) transpiration rate, (g) $\mathrm{F}_{0}$, (h) Fm, (i) Fv/Fm, (j) $\mathrm{qP}$, (k) qN, (l) $\mathrm{Y}$ (II). Data are presented as means $\pm \mathrm{SD}$ of three biological replicates. Asterisks indicate significant differences $\left({ }^{*} p<0.05,{ }^{* *} p<0.01, \mathrm{~ns} p>0.05\right)$ between the means of the treatment groups and the control groups. 
Under aluminum stress conditions, the initial fluorescence $\left(\mathrm{F}_{0}\right)$ and maximum fluorescence $(\mathrm{Fm})$ of watermelon leaves increased significantly compared with $\mathrm{CK}$, and the potential photosynthetic efficiency $(\mathrm{Fv} / \mathrm{Fm})$ and actual photosynthetic efficiency (YII) of PSII were decreased. After exogenous application of NO, no significant change in $\mathrm{F}_{0}$ and Fm was observed, while Fv/Fm and YII were significantly increased. Leaf photochemical quenching (qP) was $9.42 \%$ higher than $\mathrm{Al}$-exposed watermelon leaves, and Non-photochemical quenching (qN) was 15\% lower than Al-exposed watermelon leaves. This finding showed that NO could reduce the proportion of photosystem II (PSII) used to dissipate heat, increasing the maximum photosynthetic rate of watermelon seedlings.

\subsubsection{Effects of NO on Watermelon Leaf Stomata and Leaf Morphology under Aluminum Stress}

As shown in Figure 3, after three days of treatment, the largest stomatal width, stomatal area, and stomatal aperture were observed under aluminum stress. After exogenous application of NO, the stomatal length, stomatal width, stomatal area, and stomatal aperture were significantly reduced compared with Al-exposed watermelon leaves. It was found that $80 \%, 70 \%$, and $30 \%$ of the epidermal stomata in $\mathrm{CK}, \mathrm{Al}$, and $\mathrm{Al}+\mathrm{NO}$ were opened in leaf sections, respectively. These results indicate that NO could promote stomatal closure and reduce transpiration dissipation of watermelon leaves under aluminum stress conditions.
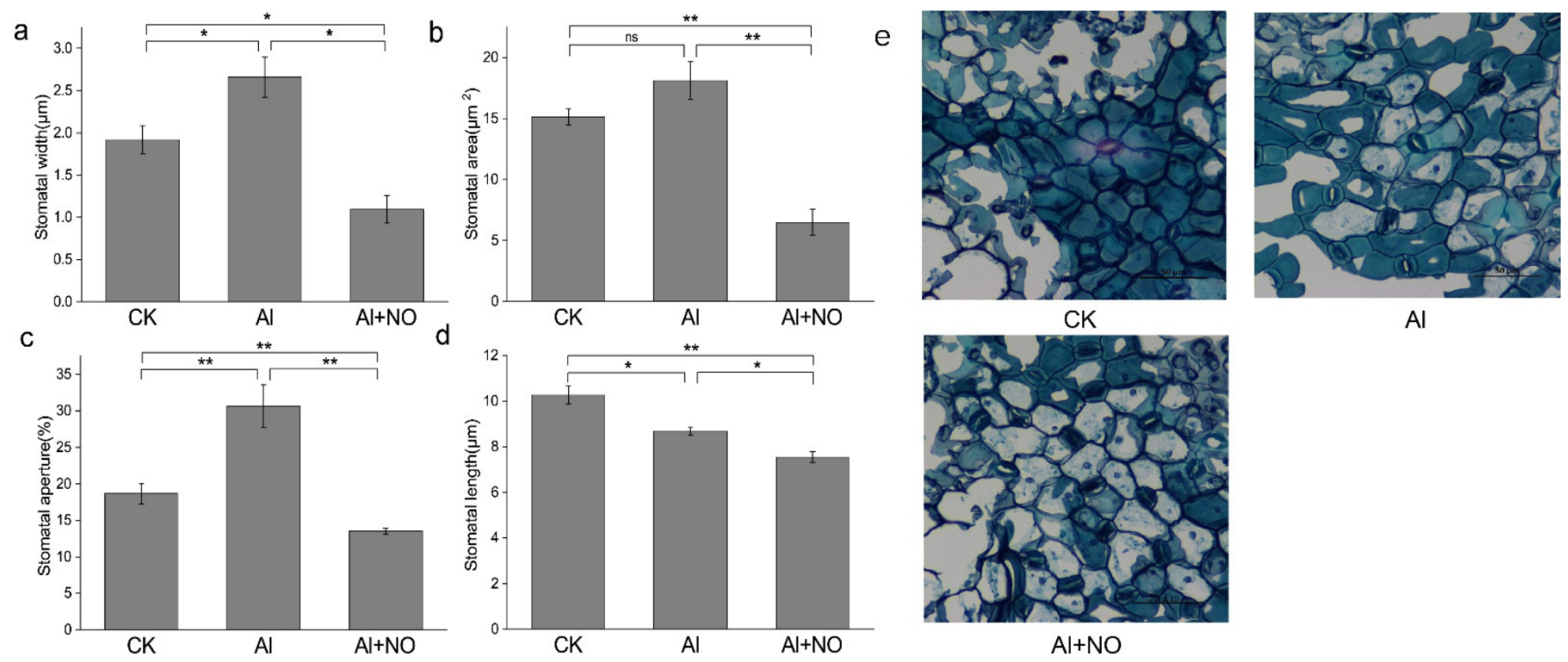

Figure 3. Effects of NO on the stomatal structure of Al-exposed watermelon leaves. (a) Stomata width, (b) stomata area, (c) stomata aperture, (d) stomata length, (e) the stomatal structure of watermelon leaves following the three different treatments. Data are presented as means $\pm \mathrm{SD}$ of three biological replicates. Asterisks indicate significant differences $\left({ }^{*} p<0.05,{ }^{* *} p<0.01\right.$, ns $\left.p>0.05\right)$ between the means of the treatment groups and the control groups.

As seen in Figure 4, aluminum stress caused changes in the morphology and anatomy of watermelon leaves. Compared with CK, aluminum stress caused a significant decrease in mesophyll thickness, disordered arrangement of palisade tissue, and dense arrangement of sponge tissues in watermelon leaves. After the exogenous application of NO, the thickness of the palisade tissue increased significantly compared with that of Al-exposed watermelon leaves, with a predominant " $Y$ " shape arrangement, while the sponge structure was loosely arranged and significantly thickened. Aluminum stress promoted increased Adaxial and Abaxial epidermis thickness, while the thickness of palisade tissue was significantly reduced by $17.27 \%$ compared with CK and the TPT/TST ratio (the ratio of palisade tissue to sponge tissue) was significantly reduced. After the exogenous application of $\mathrm{NO}$, the adaxial and abaxial epidermis thickness decreased significantly, while the mesophyll 
thickness increased significantly compared with that of Al-exposed watermelon leaves and the palisade tissue and sponge tissue increased by $36.87 \%$ and $68.45 \%$, respectively. These findings show that aluminum stress could cause thinning of watermelon leaves, and the exogenous application of $\mathrm{NO}$ could promote significant thickening of the leaf mesophyll.

a

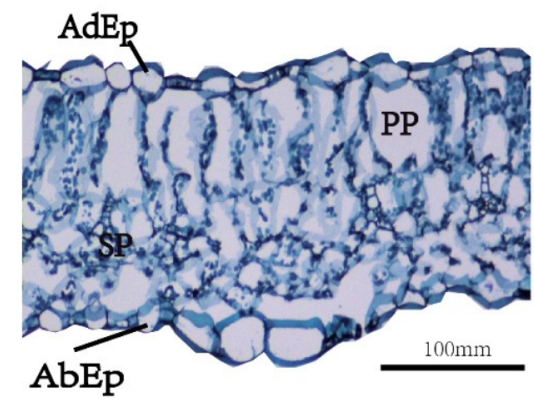

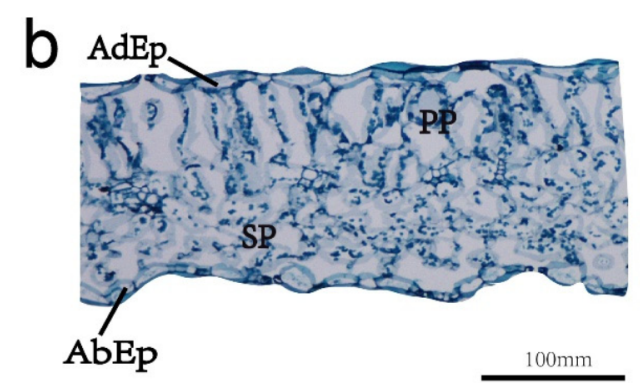

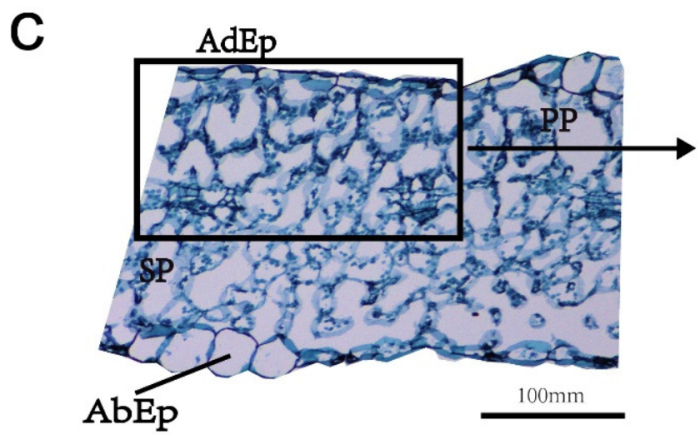

d (1)

(4)
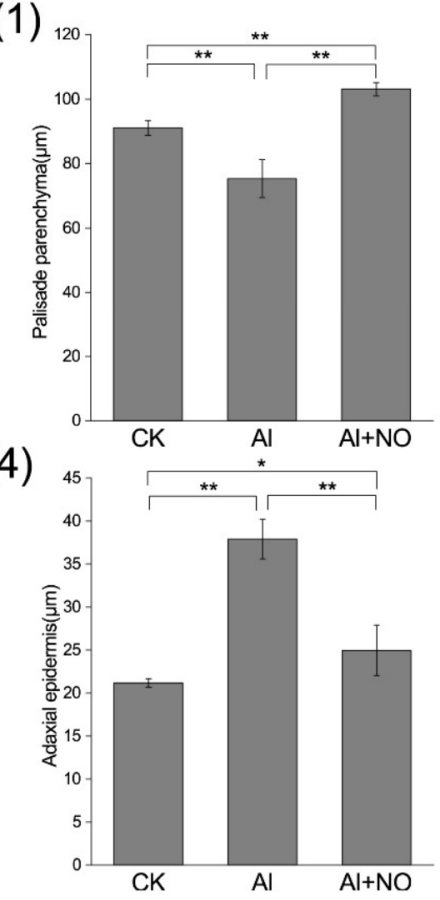

(2)

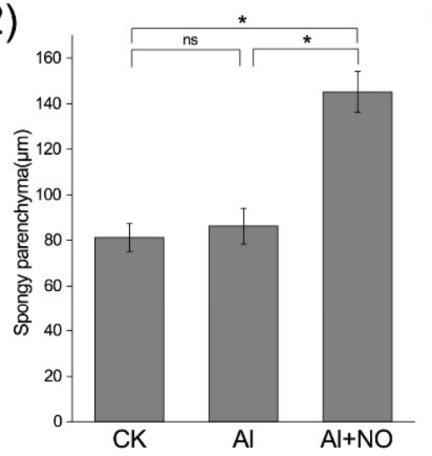

(5)

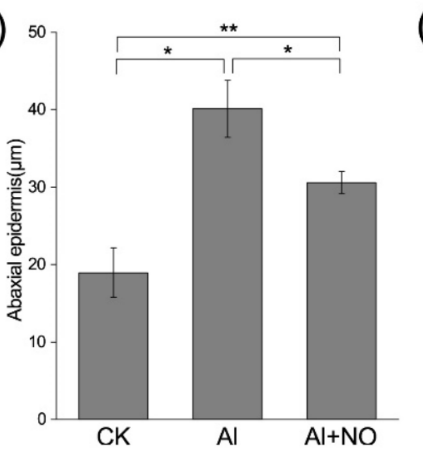

(3)

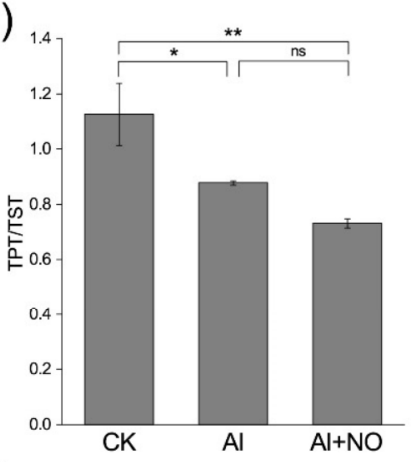

(6)

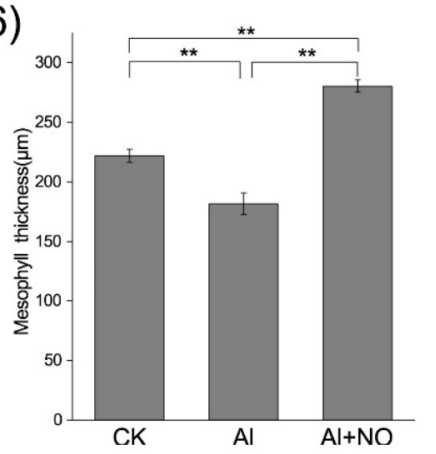

Figure 4. The effect of $\mathrm{NO}$ on the morphological structure of watermelon leaves under aluminum stress. (a-c) Leaf slices of $\mathrm{CK}, \mathrm{Al}$, and $\mathrm{Al}+\mathrm{NO}$, respectively. (d) (1) palisade tissue, (2) spongy tissue, (3) TPT/TST, (4) adaxial epidermis, (5) abaxial epidermis, (6) mesophyll thickness of watermelon leaves under three treatments. Data are presented as means \pm SD of three biological replicates. Asterisks indicate significant differences $\left({ }^{*} p<0.05,{ }^{* *} p<0.01\right.$, ns $\left.p>0.05\right)$ between the means of the treatment groups and the control groups. 
3.2.3. Effects of NO on Oxidation Stress and Nitrogen Metabolism of Watermelon Leaves under Aluminum Stress

As seen in Figure 5, compared with CK, aluminum stress inhibited peroxidase (POD), catalase (CAT), and nitrate reductase (NR) activities with decreased accumulation of nitrogen content in watermelon leaves. In contrast, aluminum stress enhanced levels of superoxide dismutase (SOD), malondialdehyde (MDA), superoxide anion content $\left(\mathrm{O}^{-}{ }^{-}\right.$), and increased electrolyte permeability. Exogenous application of NO significantly increased POD and CAT activities, alleviated cell damage under aluminum stress, decreased MDA, $\mathrm{O}^{-}$content and electrolyte permeability, and promoted NR activity and accumulation of nitrogen content.
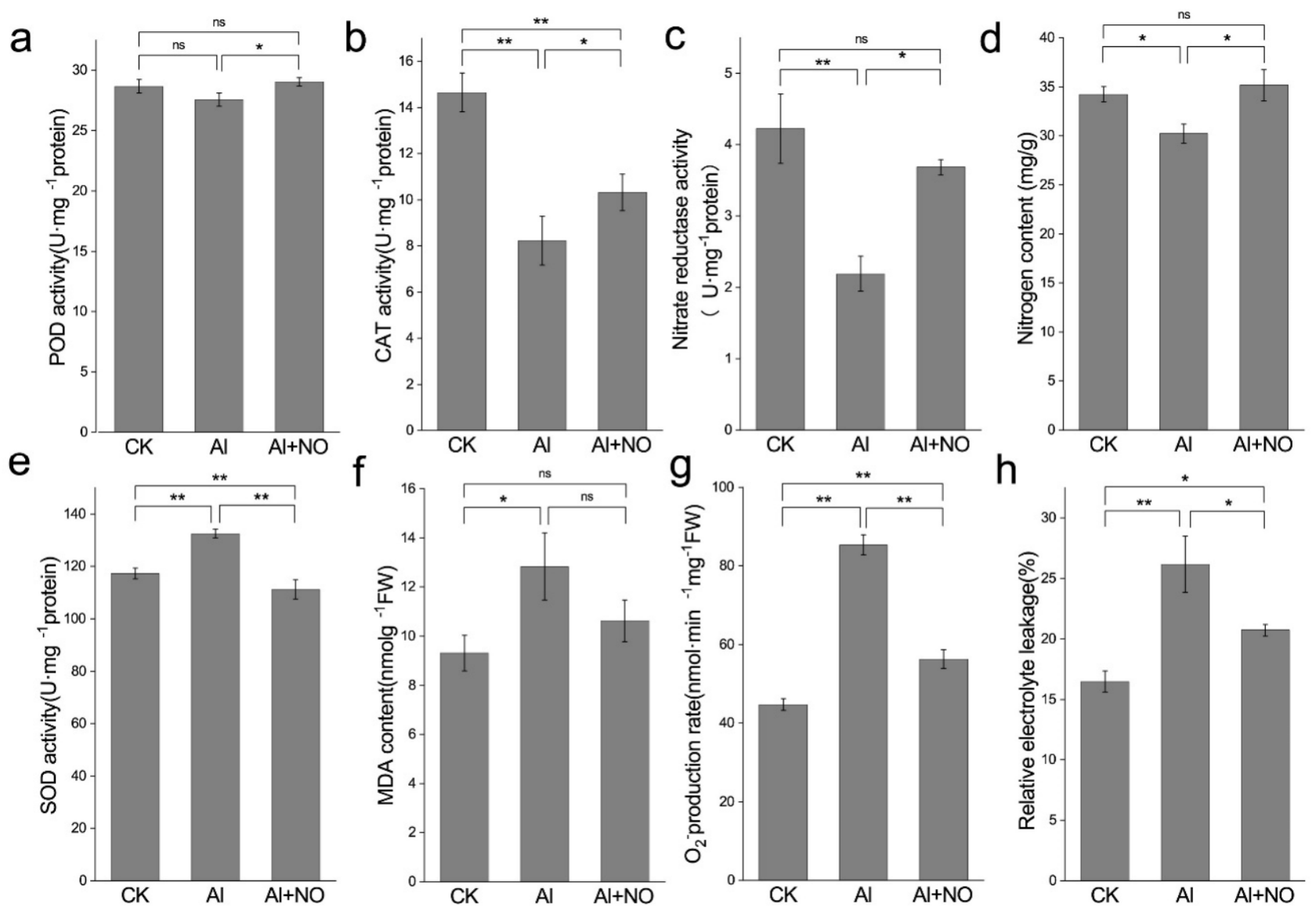

Figure 5. Effects of $\mathrm{NO}$ on oxidation stress and nitrogen metabolism of watermelon leaves under aluminum stress. (a) POD, (b) CAT, (c) NR, (d) nitrogen content, (e) SOD, (f) MDA, (g) superoxide anion, (h) relative electrical conductivity. Data are presented as means \pm SD of three biological replicates. Asterisks indicate significant differences $\left(^{*} p<0.05,{ }^{* *} p<0.01\right.$, ns $p>0.05$ ) between the means of the treatment groups and the control groups.

\subsection{Transcriptome Sequencing and Assembly}

In order to further explore the mechanisms underlying NO-induced aluminum stress alleviation, nine cDNA libraries (three samples $\mathrm{CK}, \mathrm{Al}$, and $\mathrm{Al}+\mathrm{NO}$ with three biological replicates) were constructed for transcriptome sequencing. A total of $42 \mathrm{G}$ of raw data were obtained, and the average Q20 phred score value (an error probability of $1 \%$ ) of the nine samples was greater than $97 \%$, and the average Q30 phred score value (an error probability of $0.1 \%$ ) was greater than $92 \%$ (Table S3). The watermelon genome data downloaded from http:/ / cucurbitgenomics.org/ftp/genome/watermelon/97103/v2/ (accessed on 5 April 2021) were used as the reference genome for comparison, and the similarity rate of each sample with the reference genome reached $97 \%$. This finding indicated that the transcriptome sequencing quality was high and could be further analyzed. 


\subsection{Analysis of DEGs}

The transcript abundance of genes was measured in FPKM, and the DEGs were identified based on a false discovery rate (FDR) $<0.05$ and $\mid \log 2$ (foldchange) $\mid>0$. The three comparisons ( $\mathrm{CK}$ vs. $\mathrm{Al}, \mathrm{Al}$ vs. $\mathrm{Al}+\mathrm{NO}$, and $\mathrm{CK}$ vs. $\mathrm{Al}+\mathrm{NO}$ ) yielded a total of 1544 DEGs. A total of 1107 (388 upregulated and 719 downregulated) DEGs were identified between CK and $\mathrm{Al}$ datasets, while 511 (246 upregulated and 265 downregulated) DEGs were identified between $\mathrm{Al}$ and $\mathrm{Al}+\mathrm{NO}$ datasets (Figure 6a,b).

a

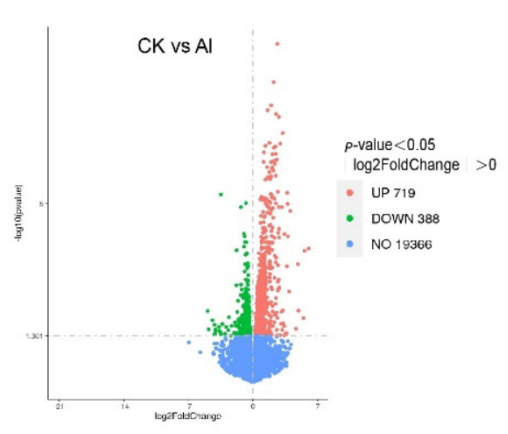

b

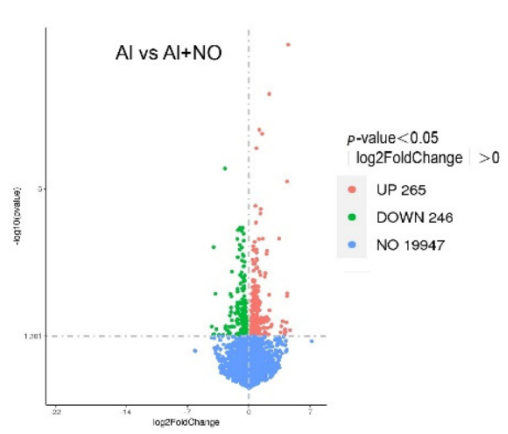

C

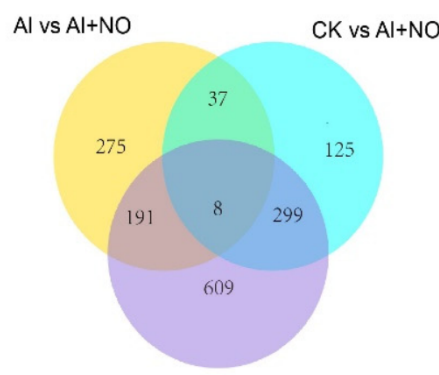

CK vs Al d

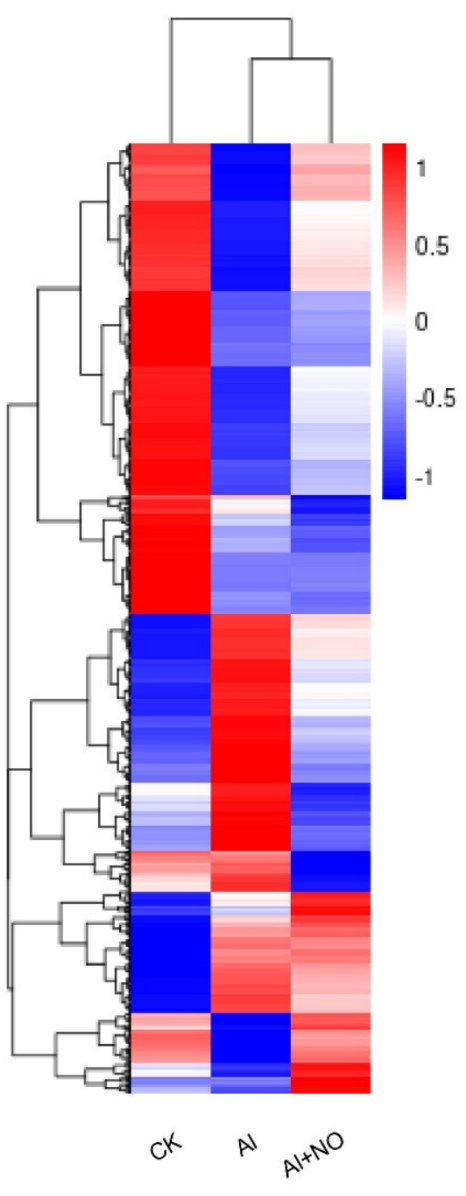

e
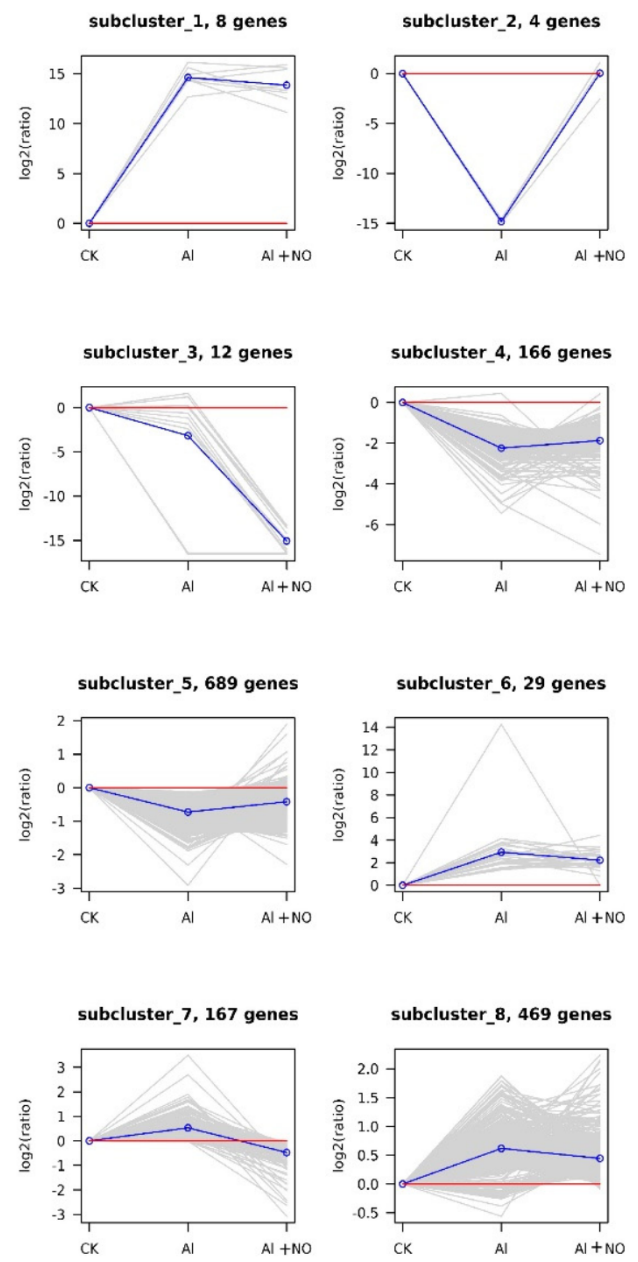

Figure 6. (a,b) Volcano map of DEGs. (c) Venn diagram of DEGs. (d) Cluster analysis results of DEGs visualized by a heatmap. The color represents the transcriptional abundance of the DEGs. Red and blue represent high and low expression levels. (e) Cluster analysis of DEGs by K-means. The gray line represents the expression of all genes in the cluster.

The intersection between $\mathrm{CK}$ vs. $\mathrm{Al}$ and $\mathrm{CK}$ vs. $\mathrm{Al}+\mathrm{NO}$ yielded $307 \mathrm{DEGs}$. After exogenous application of $\mathrm{NO}$, the number of DEGs in CK vs. $\mathrm{Al}+\mathrm{NO}$ decreased by $57.63 \%$ compared with CK vs. Al. This observation suggested that exogenous NO affected watermelon gene expression and reduced the number of DEGs compared with watermelon under aluminum stress.

To further classify the expression patterns of DEGs, the normalized value Z-score after $\log 2$ (FPKM) transformation of the 1544 DEGs was used to generate a clustered heatmap (Table S4). As seen in Figure 6e, the DEGs of CK, Al, and Al + NO were further classified into eight clusters based on their expression levels. There were 673 genes upregulated during the comparison between $\mathrm{CK}$ and $\mathrm{Al}$ datasets and downregulated when $\mathrm{Al}$ and $\mathrm{Al}+\mathrm{NO}$ datasets were compared (subgroups 1, 6, 7, 8). There were 859 genes downregulated when 
$\mathrm{CK}$ and $\mathrm{Al}$ datasets were compared and upregulated during $\mathrm{Al}$ and $\mathrm{Al}+\mathrm{NO}$ datasets comparison. According to their upregulated trend, they were divided into three subgroups (subgroups 2, 4, 5). Moreover, 12 differential genes were downregulated during the comparison between $\mathrm{CK}$ and $\mathrm{Al}$ datasets and $\mathrm{Al}$ and $\mathrm{Al}+\mathrm{NO}$ datasets. These results indicated that the exogenous application of $\mathrm{NO}$ resulted in a complex gene expression in response to aluminum stress in watermelon.

\subsection{Gene Ontology (GO) Classification and KEGG Analysis of DEGs}

GO annotation was performed to clarify the main biological functions of DEGs. The CK vs. Al comparison yielded a total of 533 GO terms, of which 294 were associated with biological processes, 39 with cellular components, and 200 with molecular functions (Table S5). Most DEGs were enriched in biological processes (BP), including photosynthesis and response to oxidative stress; cellular components (CC), including photosynthetic membrane and thylakoid; and molecular functions (MF), including peroxidase activity and antioxidant activity, indicating that aluminum stress could affect watermelon photosynthesis, destroy cells' structure, and cause oxidative damage. The comparison between $\mathrm{Al}$ and $\mathrm{Al}+\mathrm{NO}$ groups yielded $348 \mathrm{GO}$ terms, of which 166 were associated with biological processes, 15 with cellular components, and 167 belonged to molecular functions (Table S6). Among them, most DEGs were enriched in BP such as reproduction and response to oxidative stress, CC such as apoplast and extracellular region, and MF such as peroxidase activity and antioxidant activity, indicating that $\mathrm{NO}$ could alleviate the damage caused by aluminum toxicity by regulating the expression of genes involved in oxidative stress, reproduction, and apoplast pathways (Figure 7a).

We further mapped the DEGs to the Kyoto Encyclopedia of Genes and Genomes (KEGG) database to analyze the metabolic pathways. During KEGG enrichment analysis, we found that 1107 DEGs identified between CK and Al groups were annotated into 89 metabolic pathways, and 511 DEGs obtained from the $\mathrm{Al}$ vs. $\mathrm{Al}+\mathrm{NO}$ comparison were successfully annotated into 65 metabolic pathways. The top 10 pathways associated with enriched differential genes obtained from the two comparisons were statistically analyzed (Figure $7 \mathrm{~b}$ ). The top four enriched pathways during the $\mathrm{CK}$ vs. Al comparison were photosynthesis-antenna proteins $(5.41 \%)$, photosynthesis $(7.21 \%)$, plant-pathogen interaction $(10.36 \%)$, and phenylpropanoid biosynthesis $(8.55 \%)$. The top four enriched pathways obtained from $\mathrm{Al}$ vs. $\mathrm{Al}+\mathrm{NO}$ were all metabolic pathways: nitrogen metabolism $(4.50 \%)$, phenylpropanoid biosynthesis $(8.11 \%)$, porphyrin and chlorophyll metabolism $(4.50 \%)$, and arginine biosynthesis $(3.60 \%)$. This finding showed that aluminum stress could induce oxidative stress, destroying the chloroplast structure and affecting photosynthesis in watermelon leaves. The exogenous application of $\mathrm{NO}$ alleviated aluminum toxicity by influencing plant signal transmission, phenylpropane metabolism, nitrogen metabolism, and other pathways.

\subsection{Expression Analysis of Antioxidant Enzymes (SOD, POD, CAT) and NR-Related Genes}

It has been reported that aluminum stress could affect the activity of antioxidant enzymes. To further analyze the effect of $\mathrm{NO}$ on the expression of related genes, we selected 13 genes for qRT-PCR analysis (Table S7). As seen in Figure 8, SOD and CAT genes were upregulated, while $P O D$ genes were down-regulated under aluminum stress conditions. Exogenous application of NO inhibited the expression of genes coding $S O D$ and promoted the expression of genes encoding POD and CAT and three coding NR genes, consistent with the results of physiological indexes. The results suggested that NO alleviated aluminum toxicity by increasing antioxidant enzymes and $N R$ gene expression levels to relieve oxidative stress and improve nitrogen absorption in watermelon leaves. 
a
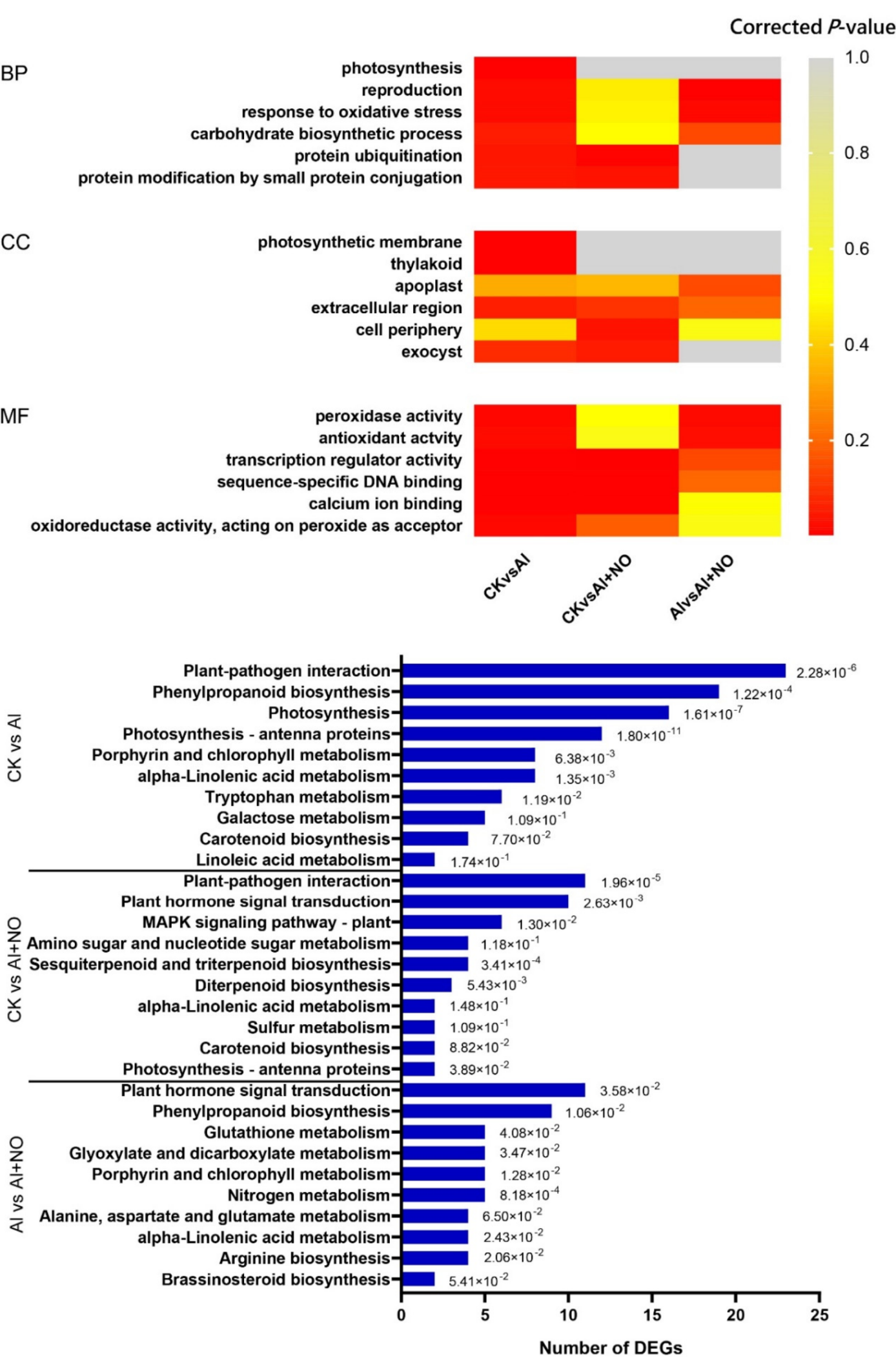

Figure 7. Annotation of DEGs. (a) GO enrichment analysis of DEGs. BP, biological process; CC, cellular component; MF, molecular function. Corrected $p$-value $<0.05$ denotes significantly enriched terms; the smaller the $p$-value, the closer the color is to red and the more significant the enrichment. (b) KEGG enrichment analysis of DEGs. The top 10 enriched terms with highly significant $p$-values $(\leq 0.05)$ in each comparison are represented. 

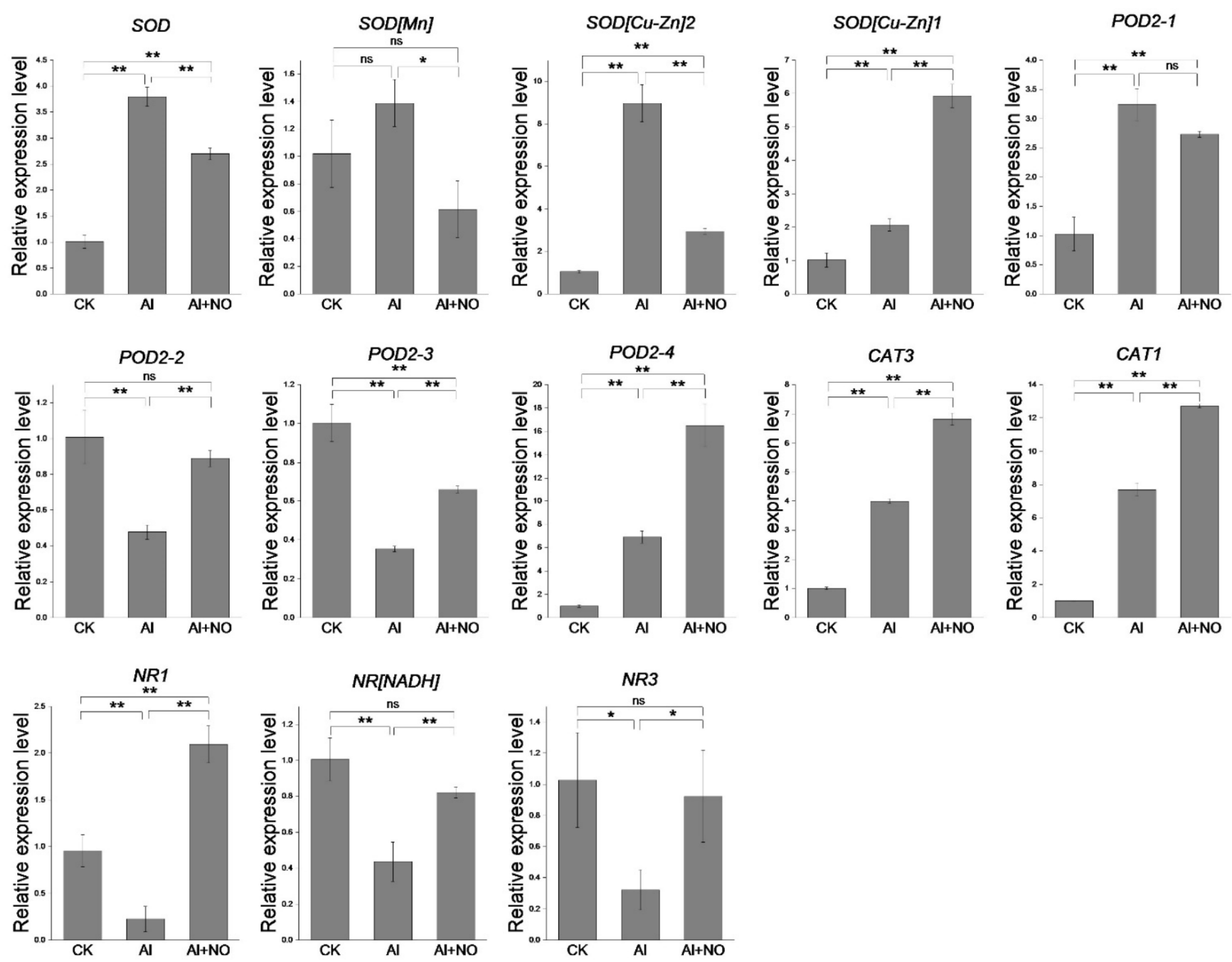

Figure 8. The effect of NO on the expression of three antioxidant enzymes and NR genes in watermelon seedlings under aluminum stress. Data are expressed as the mean $\pm \mathrm{SD}$ of three biological replicates. Data are presented as means $\pm \mathrm{SD}$ of three biological replicates. Asterisks indicate significant differences $\left({ }^{*} p<0.05,{ }^{* *} p<0.01, \mathrm{~ns} p>0.05\right)$ between the means of the treatment groups and the control groups.

\subsection{Expression Characteristics of Genes Related to Phenylpropanoid Biosynthesis}

Given that phenylpropanoids help plants respond to all aspects of biological and nonbiological stimuli, we selected 10 DEGs associated with phenylpropanoid metabolism for qRT-PCR validation. The results showed that $\mathrm{Al}$ stress promoted the upregulation of $P A L$ and $C C R$ genes and inhibited $4 C L$ gene expression in watermelon leaves. After exogenous application of NO, genes encoding $P A L, 4 C L$, and $C C R$ were significantly upregulated compared with Al-treated watermelons. In addition, five DEGs coding for $P O D$ were significantly upregulated compared with Al-treated watermelons. These results were consistent with the gene expression pattern observed during transcriptome sequencing (Figure 9a,b). 
a

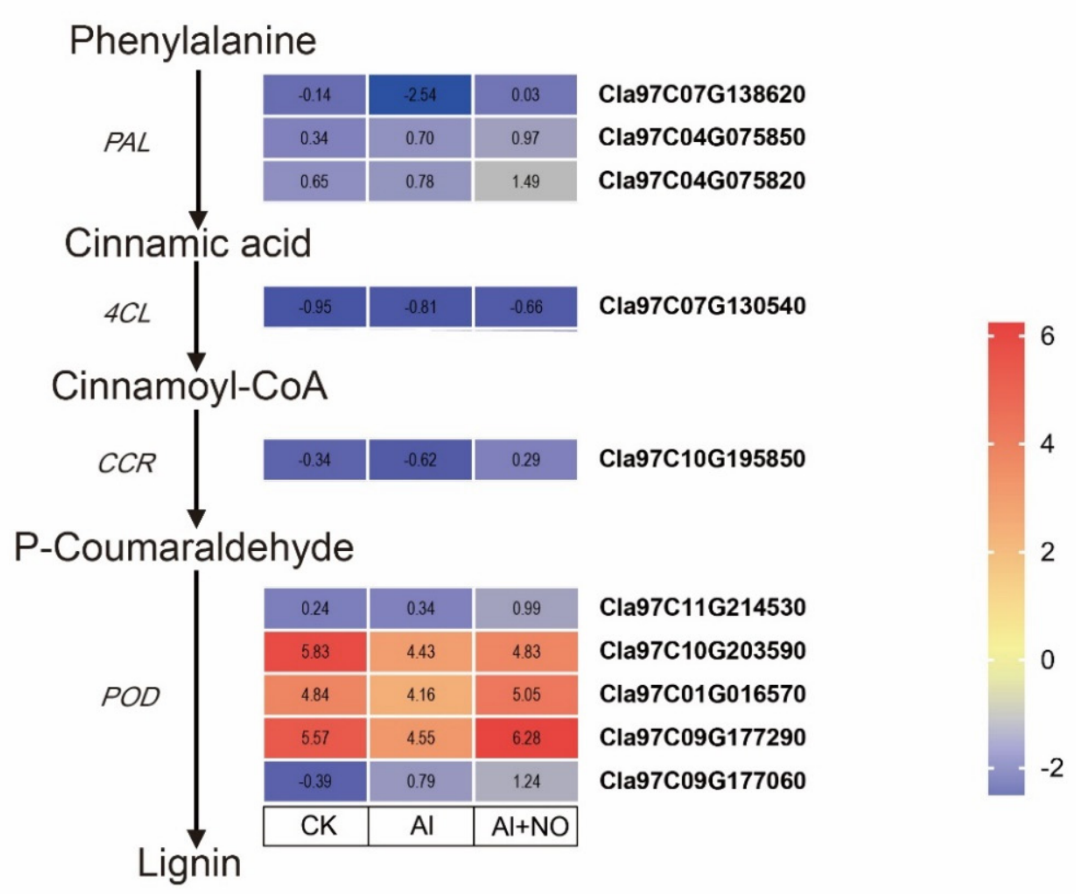

b

Cla97C07G138620

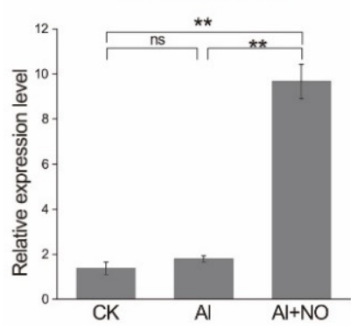

Cla97C10G195850

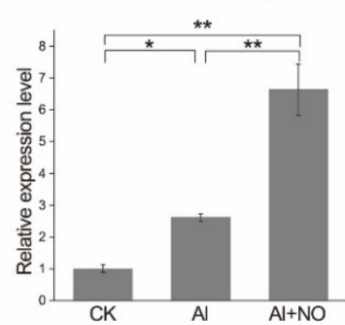

Cla97C09G177290

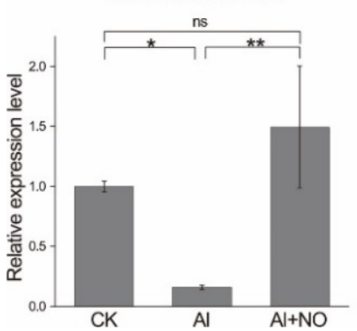

Cla97C04G075850

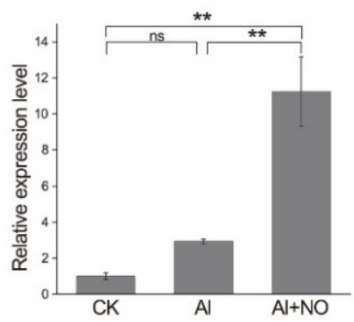

Cla97C11G214530

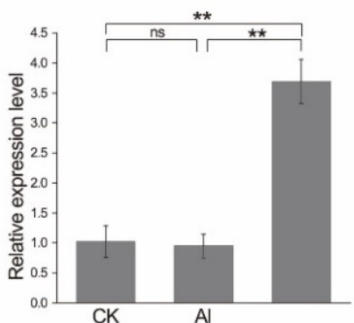

Cla97C09G177060

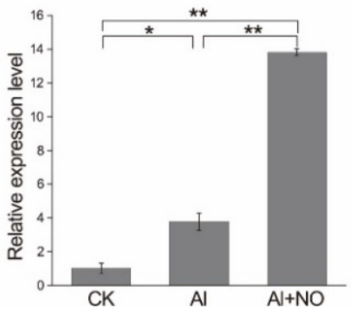

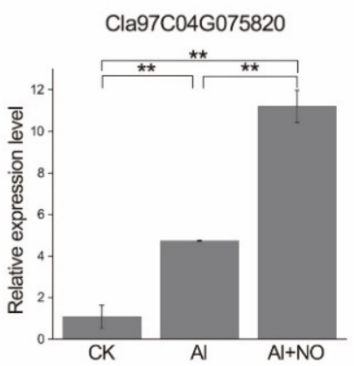

Cla97C10G203590
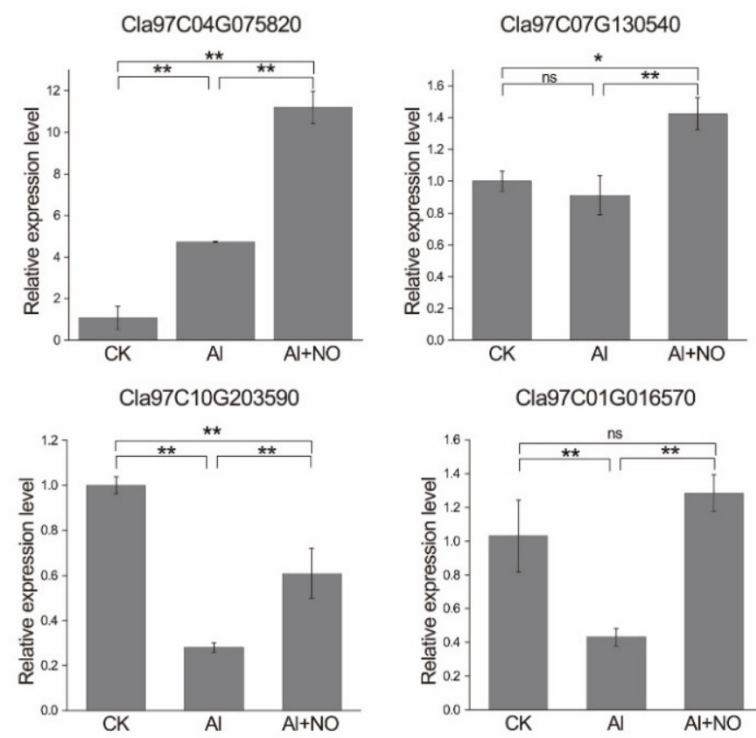

Cla97C01G016570

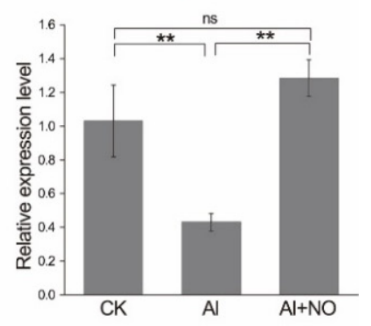

Figure 9. qRT-PCR analysis of DEGs involved in phenylpropanoid biosynthesis following the three types of treatment. (a) Heatmap showing the transcriptional abundance of DEGs. FPKM values were log2-based. Red and blue represent high and low expression levels. (b) The relative gene expression levels detected by qRT-PCR. The data are presented as the mean \pm SD of three biological and technical replicates. Data are presented as means \pm SD of three biological replicates. Asterisks indicate significant differences $\left({ }^{*} p<0.05,{ }^{* *} p<0.01, \mathrm{~ns} p>0.05\right)$ between the means of the treatment groups and the control groups. 


\section{Discussion}

High aluminum soil levels can adversely impact the growth and development of plants, resulting in low quality and yield. In general, low concentration of aluminum can promote the growth of plants, and toxic effects are observed only when the concentration of aluminum exceeds the critical tolerance threshold [20]. The characteristic appearance of aluminum toxicity is inhibition of the elongation and division of root tip cells of plants, resulting in short, coarse, and twisted roots; sparse root hairs and fibrous roots; and enlarged root tips [21]. In the present study, we found that aluminum stress significantly inhibited root elongation and the growth of watermelons, while the addition of NO alleviated growth inhibition, consistent with the literature [22,23].

It is widely acknowledged that photosynthesis plays a significant role in the overall growth of plants, and increased photosynthesis has been reported to promote plant growth [24]. Interestingly, studies have found that NO could alleviate growth inhibition of grapefruit induced by aluminum stress and could reduce damage to the photosynthetic electron transport chain [25]. Meanwhile, NO could increase photosynthesis of cucumber under cadmium stress, improve the light-harvesting complex (LHC) II and LHCI, and increase the chlorophyll fluorescence and pigment content of mustard to maintain plant water content $[26,27]$. In this study, KEGG annotation showed that the expression of structural genes encoding photosystem II reaction centers ( $P s b W, P s b Q, P s b Y)$ and photosystem I subunits (PsaD, Psae, Psaf, Psag, etc.) was downregulated under aluminum stress, indicating decreased activity of the electron transport chain and weak ability to capture light energy. After exogenous application of NO, the potential photochemical efficiency and the photochemical rate of watermelon leaves were enhanced, and the nonphotochemical quenching was reduced, consistent with the previous results. Interestingly, nitric oxide has previously been reported to improve the activity of Rubisco and Rubisco activase in tobacco under copper stress conditions [28] and promote increased ryegrass photosynthetic pigment content, leading to increased photosynthesis and growth [29]. In this study, the chlorophyll content of watermelon increased after exogenous application of NO; however, the net photosynthetic rate decreased. Since a certain linear relationship has been documented between photosynthetic rate and stomatal conductance [30], it was inferred that $\mathrm{NO}$ could promote the closure of watermelon leaves, reducing $\mathrm{CO}_{2}$ availability and weakening photosynthesis. Furthermore, by observing the cross-section of leaves, it was found that NO could increase the thickness of the watermelon parenchyma and improve the structure of the palisade tissue with a " $Y$ " shape arrangement, which greatly increased the chloroplast surface area that received light and helped to improve the potential photochemical efficiency, further improving watermelon photosynthesis.

Furthermore, high aluminum stress can induce the synthesis of active oxygen free radicals in plants, destroying the balance between free radicals and antioxidant enzymes [31]. If the active oxygen free radicals cannot be scavenged in time, damage to the cell membrane system and plasma membrane peroxidation may occur. Interestingly, a large amount of malondialdehyde reportedly causes electrolyte extravasation to increase conductivity. Studies have shown that NO plays an important role in scavenging superoxide anions and reducing plasma membrane peroxidation. Most importantly, NO can enhance the activity of POD, SOD, and CAT in the root tip of rice under aluminum stress conditions, reduce the accumulation of MDA and ${ }^{--}$, enhance the activity of the antioxidant system of mung bean under cadmium stress, and prevent membrane lipid peroxidation [32,33]. In the present study, the $\mathrm{O}^{--}$concentration in watermelon leaves increased significantly under aluminum stress, which caused plasma membrane peroxidation, leading to a significant increase in MDA and electrical conductivity. After the exogenous application of NO, the activity of POD and CAT enzymes was increased while the expression of genes encoding $P O D$ and $C A T$ was significantly upregulated, consistent with the physiological results.

It is widely acknowledged that nitrate reductase (NR) plays a crucial role in catalyzing nitrate reduction and nitrogen metabolism. Accordingly, nitrate reductase activity can be used to quantify nitrogen metabolism [34,35]. During annotation analysis, we found that 
many DEGs were significantly enriched in the nitrogen metabolism pathway. By analyzing the relative expression levels of three genes that encode $N R$, we found that aluminum stress could inhibit NR gene expression, while NO significantly promoted the upregulation of $N R$ gene expression. In addition, NR activity and nitrogen content of watermelon leaves under aluminum stress significantly decreased compared with $\mathrm{CK}$, while exogenous application of NO promoted NR activity and nitrogen content. This finding suggests that NO could affect nitrate reductase activity by regulating $N R$ gene expression to promote nitrogen absorption.

Phenylpropanoid metabolism plays an important role in plant development and its ability to cope with adversity. The synthesized metabolites mainly include lignins and flavonoids [36]. In this regard, the major function of lignins is to increase the mechanical strength and rigidity of the cell wall and promote the formation of xylem ducts to transport water and nutrients over long distances [37], while flavonoids have been reported to reduce oxidative damage caused by reactive oxygen species [38]. In our study, we found that DEGs were significantly enriched in phenylpropanoid metabolism after exogenous application of $\mathrm{NO}$, and genes encoding $P A L, 4 C L$, and $C C R$ were significantly upregulated. Among them, $P A L$ and $4 C L$ are key enzymes involved in plant phenylpropanoid metabolism, which provide precursors for synthesizing downstream metabolites [39]. Furthermore, CCR is a key enzyme for lignin synthesis, which converts hydroxycinnamyl-CoA ester into the corresponding hydroxycinnamaldehyde, which plays an important role in coping with biological stress [40,41]. Importantly, class III peroxidases (POD) can reportedly oxidize different substrates with $\mathrm{H}_{2} \mathrm{O}_{2}$ as the electron donor [42]. Studies have shown that the inhibition of class III peroxidases could inhibit the entire lignin biosynthesis pathway [43]. In this study, five genes encoding class III peroxidases were significantly upregulated, indicating that NO could affect the expression of phenylpropanoid metabolism-related genes, promote lignin biosynthesis, and synthesize peroxidases to alleviate oxidative damage induced by aluminum stress to better protect leaf structure and promote watermelon growth. These results indicate that NO plays an important role in alleviating aluminum stress in watermelon, providing new insights into the molecular mechanisms underlying the response in watermelon leaves to aluminum stress, and providing a new approach to tackle the effects of aluminum toxicity in watermelon.

Supplementary Materials: The following are available online at https: / www.mdpi.com/article/ 10.3390/genes12111735/s1. Table S1: Concentration of RNA and detection of RIN value. Table S2: Primers used in this experiment and their sequences. Table S3: Transcriptome sequencing quality assessment. Table S4: 1544 DEGs of the three comparison groups. Table S5: GO enrichment analysis of DEGs of CK vs. Al. Table S6: GO enrichment analysis of DEGs of Al vs. Al + NO. Table S7: Transcriptional abundance of three antioxidant enzymes and NR genes.

Author Contributions: Conceptualization, M.L. and Y.Z.; data curation, J.X.; formal analysis, J.M. and J.X.; investigation, J.L. and M.H.; software, K.Z.; writing-original draft preparation, Y.Z. and J.X.; writing-review and editing, M.L.; funding acquisition, Y.Z. All authors have read and agreed to the published version of the manuscript.

Funding: The work was supported by grants from the Science and Technology Plan Project of Sichuan Province (grant no. 2019ZHFP0268).

Institutional Review Board Statement: Not applicable.

Informed Consent Statement: Not applicable.

Data Availability Statement: The transcriptome sequence data generated in this study were deposited at: https: / / www.ncbi.nlm.nih.gov / bioproject?term=prjna769969.

Conflicts of Interest: The authors declare no conflict of interest. 


\section{References}

1. Guo, S.; Zhang, J.; Sun, H.; Salse, J.; Lucas, W.J.; Zhang, H.; Zheng, Y.; Mao, L.; Ren, Y.; Wang, Z.; et al. The draft genome of watermelon (Citrullus lanatus) and resequencing of 20 diverse accessions. Nat. Genet. 2013, 45, 51-58. [CrossRef] [PubMed]

2. Grisel, N.; Zoller, S.; Künzli-Gontarczyk, M.; Lampart, T.; Münsterkötter, M.; Brunner, I.; Bovet, L.; Métraux, J.-P.; Sperisen, C. Transcriptome responses to aluminum stress in roots of aspen (Populus tremula). BMC Plant Biol. 2010, 10, 185. [CrossRef] [PubMed]

3. Von Uexküll, H.R.; Mutert, E. Global extent, development and economic impact of acid soils. Plant Soil 1995, 171, 1-15. [CrossRef]

4. Ma, J.F. Syndrome of Aluminum Toxicity and Diversity of Aluminum Resistance in Higher Plants. Adv. Virus Res. 2007, 264, 225-252. [CrossRef]

5. Malangisha, G.K.; Yang, Y.; Moustafa-Farag, M.; Fu, Q.; Shao, W.; Wang, J.; Shen, L.; Huai, Y.; Lv, X.; Shi, P.; et al. Subcellular distribution of aluminum associated with differential cell ultra-structure, mineral uptake, and antioxidant enzymes in root of two different Al+3-resistance watermelon cultivars. Plant Physiol. Biochem. 2020, 155, 613-625. [CrossRef] [PubMed]

6. Fan, W.; Xu, J.M.; Wu, P.; Yang, Z.X.; Lou, H.Q.; Chen, W.W.; Jin, J.F.; Zheng, S.J.; Yang, J.L. Alleviation by abscisic acid of Al toxicity in rice bean is not associated with citrate efflux but depends on ABI5-mediated signal transduction pathways. J. Integr. Plant Biol. 2018, 61, 140-154. [CrossRef] [PubMed]

7. Paul, S.; Roychoudhury, A. Regulation of physiological aspects in plants by hydrogen sulfide and nitric oxide under challenging environment. Physiol. Plant. 2019, 168, 374-393. [CrossRef]

8. Polverari, A.; Molesini, B.; Pezzotti, M.; Buonaurio, R.; Marte, M.; Delledonne, M. Nitric Oxide-Mediated Transcriptional Changes in Arabidopsis thaliana. Mol. Plant-Microbe Interact. 2003, 16, 1094-1105. [CrossRef]

9. Nabi, R.B.S.; Tayade, R.; Hussain, A.; Kulkarni, K.P.; Imran, Q.M.; Mun, B.-G.; Yun, B.-W. Nitric oxide regulates plant responses to drought, salinity, and heavy metal stress. Environ. Exp. Bot. 2019, 161, 120-133. [CrossRef]

10. Yang, L.-T.; Qi, Y.-P.; Chen, L.-S.; Sang, W.; Lin, X.-J.; Wu, Y.-L.; Yang, C.-J. Nitric oxide protects sour pummelo (Citrus grandis) seedlings against aluminum-induced inhibition of growth and photosynthesis. Environ. Exp. Bot. 2012, 82, 1-13. [CrossRef]

11. Bai, X.Y.; Dong, Y.J.; Wang, Q.H.; Xu, L.L.; Kong, J.; Liu, S. Effects of lead and nitric oxide on photosynthesis, antioxidative ability, and mineral element content of perennial ryegrass. Biol. Plant. 2014, 59, 163-170. [CrossRef]

12. Wang, H.; Li, Y.; Hou, J.; Huang, J.; Liang, W. Nitrate reductase-mediated nitric oxide production alleviates Al-induced inhibition of root elongation by regulating the ascorbate-glutathione cycle in soybean roots. Plant Soil 2017, 410, 453-465. [CrossRef]

13. Marciano, D.P.D.R.O.; Flávia, T.R.; Alvim, M.N.; Magalhaes, J.R.; Frana, M.G.C. Nitric oxide reduces the stress effects of aluminum on the process of germination and early root growth of rice. J. Plant Nutr. Soil Sci. 2010, 173, 885-891. [CrossRef]

14. Li, D.; Ma, W.; Wei, J.; Mao, Y.; Peng, Z.; Zhang, J.; Kong, X.; Han, Q.; Fan, W.; Yang, Y.; et al. Magnesium promotes root growth and increases aluminum tolerance via modulation of nitric oxide production in Arabidopsis. Plant Soil 2020, 457, 83-95. [CrossRef]

15. Chen, T.-K.; Yang, H.-T.; Fang, S.-C.; Lien, Y.-C.; Yang, T.-T.; Ko, S.-S. Hybrid-Cut: An Improved Sectioning Method for Recalcitrant Plant Tissue Samples. J. Vis. Exp. 2016, e54754. [CrossRef]

16. Cao, K.; Yu, J.; Xu, D.; Ai, K.; Bao, E.; Zou, Z. Exposure to lower red to far-red light ratios improve tomato tolerance to salt stress. BMC Plant Biol. 2018, 18, 92. [CrossRef]

17. Leleu, O.; Vuylsteker, C. Unusual regulatory nitrate reductase activity in cotyledons of Brassica napus seedlings: Enhancement of nitrate reductase activity by ammonium supply. J. Exp. Bot. 2004, 55, 815-823. [CrossRef]

18. Ferrari, A.; Catanzaro, E.; Russo-Alesi, F. Nitrogen Analysis by a Continuous Digestion System. Ann. N. Y. Acad. Sci. 1965, 130, 602-620. [CrossRef]

19. Pfaffl, M.W. A new mathematical model for relative quantification in real-time RT-PCR. Nucleic Acids Res. 2001, 29, e45. [CrossRef]

20. Zhao, L.; Cui, J.; Cai, Y.; Yang, S.; Liu, J.; Wang, W.; Gai, J.; Hu, Z.; Li, Y. Comparative Transcriptome Analysis of Two Contrasting Soybean Varieties in Response to Aluminum Toxicity. Int. J. Mol. Sci. 2020, 21, 4316. [CrossRef]

21. Kapoor, D.; Singh, S.; Kumar, V.; Romero, R.; Prasad, R.; Singh, J. Antioxidant enzymes regulation in plants in reference to reactive oxygen species (ROS) and reactive nitrogen species (RNS). Plant Gene 2019, 19, 100182. [CrossRef]

22. Tiwari, S.; Verma, N.; Singh, V.P.; Prasad, S.M. Nitric oxide ameliorates aluminium toxicity in Anabaena PCC 7120: Regulation of aluminium accumulation, exopolysaccharides secretion, photosynthesis and oxidative stress markers. Environ. Exp. Bot. 2019, 161, 218-227. [CrossRef]

23. Gupta, N.; Gaurav, S.S.; Kumar, A. Molecular Basis of Aluminium Toxicity in Plants: A Review. Am. J. Plant Sci. 2013, $04,21-37$. [CrossRef]

24. Kirschbaum, M.U. Does Enhanced Photosynthesis Enhance Growth? Lessons Learned from $\mathrm{CO}_{2}$ Enrichment Studies. Plant Physiol. 2011, 155, 117-124. [CrossRef]

25. Rather, B.A.; Mir, I.R.; Sehar, Z.; Anjum, N.A.; Masood, A.; Khan, N.A. The outcomes of the functional interplay of nitric oxide and hydrogen sulfide in metal stress tolerance in plants. Plant Physiol. Biochem. 2020, 155, 523-534. [CrossRef]

26. Gong, B.; Nie, W.; Yan, Y.; Gao, Z.; Shi, Q. Unravelling cadmium toxicity and nitric oxide induced tolerance in Cucumis sativus: Insight into regulatory mechanisms using proteomics. J. Hazard. Mater. 2017, 336, 202-213. [CrossRef]

27. Per, T.S.; Masood, A.; Khan, N.A. Nitric oxide improves S-assimilation and GSH production to prevent inhibitory effects of cadmium stress on photosynthesis in mustard (Brassica juncea L.). Nitric Oxide 2017, 68, 111-124. [CrossRef] 
28. Khairy, A.I.H.; Oh, M.J.; Lee, S.M.; Kim, D.S.; Roh, K.S. Nitric oxide overcomes Cd and Cu toxicity in in vitro-grown tobacco plants through increasing contents and activities of rubisco and rubisco activase. Biochim. Open 2016, 2, 41-51. [CrossRef]

29. Dong, Y.; Xu, L.; Wang, Q.; Fan, Z.; Kong, J.; Bai, X. Effects of exogenous nitric oxide on photosynthesis, antioxidative ability, and mineral element contents of perennial ryegrass under copper stress. J. Plant Interact. 2013, 9, 402-411. [CrossRef]

30. Wong, S.C.; Cowan, I.R.; Farquhar, G. Stomatal conductance correlates with photosynthetic capacity. Nat. Cell Biol. 1979, 282, 424-426. [CrossRef]

31. Zhang, X.; Tong, T.; Tian, B.; Fang, Y.; Pan, J.; Zheng, J.; Xue, D. Physiological, Biochemical and Molecular Responses of Barley Seedlings to Aluminum Stress. Phyton 2019, 88, 253-260. [CrossRef]

32. Lan, Y.; Chai, Y.; Xing, C.; Wu, K.; Wang, L.; Cai, M. Nitric oxide reduces the aluminum-binding capacity in rice root tips by regulating the cell wall composition and enhancing antioxidant enzymes. Ecotoxicol. Environ. Saf. 2021, 208, 111499. [CrossRef] [PubMed]

33. Li, S.-W.; Li, Y.; Leng, Y.; Zeng, X.-Y.; Ma, Y.-H. Nitric oxide donor improves adventitious rooting in mung bean hypocotyl cuttings exposed to cadmium and osmotic stresses. Environ. Exp. Bot. 2019, 164, 114-123. [CrossRef]

34. Sharma, A.; Soares, C.; Sousa, B.; Martins, M.; Kumar, V.; Shahzad, B.; Sidhu, G.P.; Bali, A.S.; Asgher, M.; Bhardwaj, R.; et al. Nitric oxide-mediated regulation of oxidative stress in plants under metal stress: A review on molecular and biochemical aspects. Physiol. Plant. 2019, 168, 318-344. [CrossRef]

35. Yamasaki, H.; Sakihama, Y. Simultaneous production of nitric oxide and peroxynitrite by plant nitrate reductase: In vitro evidence for the NR-dependent formation of active nitrogen species. FEBS Lett. 2000, 468, 89-92. [CrossRef]

36. Gray, J.; Caparrós-Ruiz, D.; Grotewold, E. Grass phenylpropanoids: Regulate before using! Plant Sci. 2012, 184, 112-120. [CrossRef]

37. Zhao, Q. Lignification: Flexibility, Biosynthesis and Regulation. Trends Plant Sci. 2016, 21, 713-721. [CrossRef]

38. Jiang, N.; Doseff, A.I.; Grotewold, E. Flavones: From Biosynthesis to Health Benefits. Plants 2016, 5, 27. [CrossRef]

39. Ponniah, S.K.; Shang, Z.; Akbudak, M.A.; Srivastava, V.; Manoharan, M. Down-regulation of hydroxycinnamoyl CoA: Shikimate hydroxycinnamoyl transferase, cinnamoyl CoA reductase, and cinnamyl alcohol dehydrogenase leads to lignin reduction in rice (Oryza sativa L. ssp. japonica cv. Nipponbare). Plant Biotechnol. Rep. 2017, 11, 17-27. [CrossRef]

40. Jardim-Messeder, D.; Felix-Cordeiro, T.; Barzilai, L.; De Souza-Vieira, Y.; Galhego, V.; Bastos, G.A.; Valente-Almeida, G.; Aiube, Y.R.A.; Faria-Reis, A.; Corrêa, R.L.; et al. Genome-wide analysis of general phenylpropanoid and monolignol-specific metabolism genes in sugarcane. Funct. Integr. Genom. 2021, 21, 73-99. [CrossRef]

41. Park, H.L.; Bhoo, S.H.; Kwon, M.; Lee, S.-W.; Cho, M.-H. Biochemical and Expression Analyses of the Rice Cinnamoyl-CoA Reductase Gene Family. Front. Plant Sci. 2017, 8, 2099. [CrossRef]

42. Marjamaa, K.; Kukkola, E.M.; Fagerstedt, K.V. The role of xylem class III peroxidases in lignification. J. Exp. Bot. 2009, 60, 367-376. [CrossRef]

43. Fernández-Pérez, F.; Pomar, F.; Pedreño, M.A.; Novo-Uzal, E. Suppression of Arabidopsis peroxidase 72 alters cell wall and phenylpropanoid metabolism. Plant Sci. 2015, 239, 192-199. [CrossRef] 